\title{
Analysis and Research of Methods of Linearization of the Transfer Function of Precision Semiconductor Temperature Sensors
}

\author{
${ }^{1}$ Danylo Halytsky Lviv National Medical University, Lviv, Ukraine, oxana_bojko@ukr.net \\ ${ }^{2}$ Lviv Polytechnic National University, Lviv, Ukraine, zhotra@polynet.lviv.ua
}

\begin{abstract}
The analysis of nonlinearity of the transfer function of primary temperature transducers based on transistor structures has been performed. It's shown that the quadratic component of the transfer function creates a significant nonlinearity error up to $0.2-0.6^{\circ} \mathrm{C}$. We have developed methods of linearization based on both the formation of compensatory measuring current and change of the conversion factor of the output scaling amplifier at certain ranges of temperature measurement, which ensure their use in precision temperature measuring devices. The investigation of the developed schematic diagram has shown that in the case of usage the linearisation method based on the formation of compensating base current, the measurement accuracy of $\pm 0.01{ }^{\circ} \mathrm{C}$ is provided. At the application of the method with a variable conversion factor of output scaling amplifier, the accuracy of $\pm 0.005^{\circ} \mathrm{C}$ is provided in the range $30-100^{\circ} \mathrm{C}$.
\end{abstract}

Keywords: transistor, temperanure sensor, linearisation.

Received 19 August 2020; Accepted 15 December 2020.

\section{Introduction}

Temperature sensors are widely used in measuring and control systems for laboratory, industrial and home applications. High accuracy, linearity, sensitivity, low power consumption are the main requirements for such sensors [1-3]. To conduct biomedical research, it is important to create precision temperature sensors in the range $30-100^{\circ} \mathrm{C}$.

A significant number of modern temperature sensors in the measurement range from $0^{\circ} \mathrm{C}$ to $+120^{\circ} \mathrm{C}$ use semiconductor transistor structures as primary transducers [2]. Modern transistors are characterized by extremely small size (from millimeters to micrometers), and temperature sensors based on them, provide significantly higher temperature sensitivity compared with resistance temperature detectors (RTDs) or thermocouples [2]. In addition, the use of transistors opens up the possibility of expanding functionality, in particular, providing both temperature measurement and controlled heating $[4,5]$.

Primary temperature transducers based on transistor structures provide high sensitivity. In particular when the temperature dependence of the base-emitter voltage is used as an informative value, the sensitivity equals $2 \mathrm{mV} /{ }^{\circ} \mathrm{C}$ [6]. The main disadvantages of transistor structures are the significant variation of temperaturedependent characteristics $\left( \pm 10^{\circ} \mathrm{C}\right)$ and the nonlinearity of the transfer function. To reduce the impact of the scatter of the characteristics in the operating conditions, additional calibration of the characteristics of the transistor structures is performed. Compensation of the nonlinearity of the temperature dependence of the baseemitter voltage can be performed by digital and analogue methods. In digital methods, special linearization algorithms are used. Additional linearization schemes are used in analogue methods. The advantage of analogue methods is their ability to be implemented for different types of the secondary measuring devices.

\section{Analysis of temperature-dependent characteristics of transistor structures}

The dependence of the transistor base-emitter 
voltage on the temperature change is described by the equation:

$$
U_{b e t}=U_{b e t 0}-\Delta U_{A} t-\Delta U_{B} t^{2}
$$

where $U_{\text {beto }}$ is the value of the base-emitter voltage at $t=$ $0^{\circ} \mathrm{C} ; \Delta U_{A}$ is the linear coefficient of change of baseemitter voltage from temperature; $\Delta U_{B}$ is the quadratic coefficient of change of base-emitter voltage from temperature; $t$ is the value of the measured temperature.

The linear coefficient is mainly determined at the temperature of $0{ }^{\circ} \mathrm{C}$ or at the temperature of the initial value of the measuring range with a corresponding change in temperature by $1{ }^{\circ} \mathrm{C}$.

The quadratic coefficient of the base-emitter voltage change equals:

$$
\Delta U_{B}=\frac{U_{b e t 0}-U_{b e t m}-\Delta U_{A} t_{m}}{t_{m}^{2}},
$$

where $U_{\text {betm }}$ is the value of the base-emitter voltage at the maximum value of the temperature measurement range $t_{m}$.

The change in base-emitter voltage from temperature is described as follows:

$$
\Delta U_{b e t}=-\Delta U_{A} t-\Delta U_{B} t^{2} .
$$

To obtain the value of the output voltage numerically equal to the value of the measured temperature, it is necessary to calibrate the output voltage at the end of the temperature range according to the expression.

$$
t_{m} \cdot 10 m V /{ }^{\circ} C=\left(\Delta U_{A} t+\Delta U_{B} t^{2}\right) k,
$$

where $k$ is the gain factor of the output scale amplifier.

The effect of the quadratic component is fully compensated and the equivalent value of the linear coefficient is equal to:

$$
\Delta U_{A}=\frac{10 \mathrm{MB} /{ }^{\circ} \mathrm{C}}{k} .
$$

The nonlinearity error is described as follows:

$$
\Delta_{l}=\left(\Delta U_{A} t+\Delta U_{B} t^{2}\right) k-t \cdot 10 \mathrm{mV} /{ }^{\circ} \mathrm{C} .
$$

The optimal value of the nonlinearity error can be ensured by the optimal choice of calibration points on individual measurement ranges.

Graphical dependences of nonlinearity errors for different calibration points for $\Delta U_{A}=1.882 \mathrm{mV} /{ }^{\circ} \mathrm{C}$ and $\Delta U_{B}=0.41 \mu \mathrm{V} /{ }^{\circ} \mathrm{C}^{2}$ are depicted in Fig. 1 .

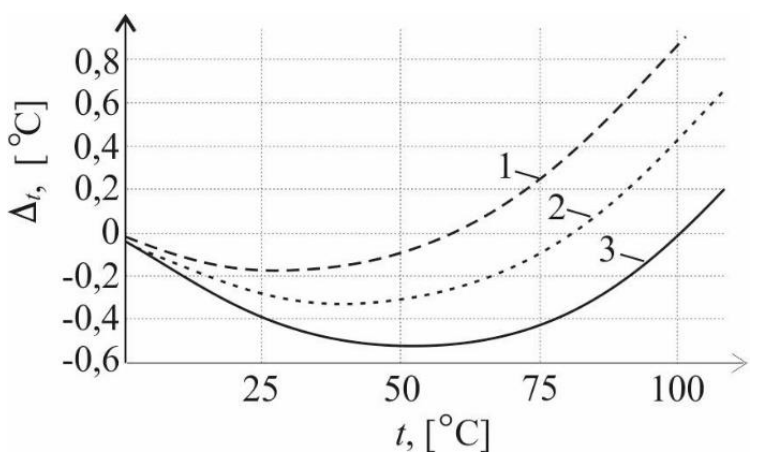

Fig. 1. Dependences of nonlinearity errors during calibration at points: $1-60^{\circ} \mathrm{C}, 2-80^{\circ} \mathrm{C}, 3-100^{\circ} \mathrm{C}$.

As can be seen from the plots, the reduction of the nonlinearity error is achieved by reducing the measurement range, It does not exceed $0.53^{\circ} \mathrm{C}$ over the range $0 \ldots 100^{\circ} \mathrm{C}, 0.32^{\circ} \mathrm{C}$ over the range $0 \ldots 80^{\circ} \mathrm{C}$, and $0.19^{\circ} \mathrm{C}$ over the range $0 \ldots 60^{\circ} \mathrm{C}$.

\section{The method of linearization based on the change of the measuring current of the transistor primary transduser}

The linearization of the PTT transfer function can be performed by forming an additional compensation current through the PTT in the linearization range.

The structural scheme of the temperature sensor with the formation of the base compensating current is shown in Fig. 2.

The transistor PTT is connected to a secondary temperature transducer (STT), which contains an inverting input amplifier (IIA), a former of the measurement current (FMC), an output scale summing amplifier (OSSA), a former of the compensating voltage (FCV), a linearization device (LD) and a bias voltage generator $(\mathrm{BVG})$.

When the reference measuring current passes through the PTT at the output of the IIA the voltage is formed:

$$
U_{1}=U_{b e 0}-\Delta U_{A} t-\Delta U_{B} t^{2}
$$

The former of the compensating voltage FCV is used

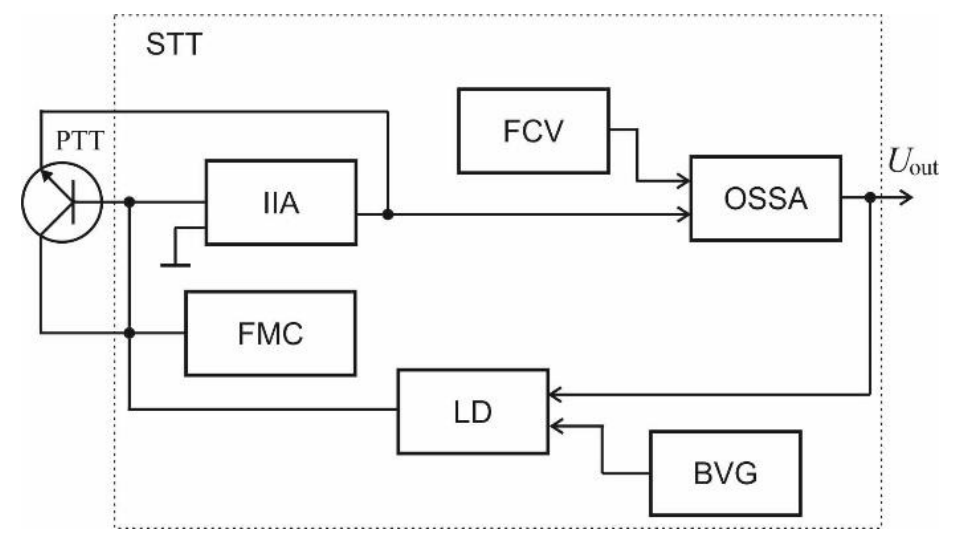

Fig. 2. Structural scheme of the temperature sensor with the formation of the base compensating current. 
for compensation of $\mathrm{U}_{\mathrm{be} 0}$. In this case, a voltage at the output of the OSSA is described by the following expression:

$$
U_{\text {out }}=\left(-\Delta U_{A} t-\Delta U_{B} t^{2}\right) k
$$

where $k$ is the conversion factor of the OSSA.

The value of the coefficient $k$ is chosen from the condition of ensuring the numerical equality of the output voltage to the value of the measured temperature at the calibration point.

In the linearization range, the LD generates compensation current:

$$
I_{c}=\left(U_{\text {out }}-U_{z}\right) k_{l},
$$

where $U_{z}$ is the bias voltage, the value of which is equal to $U_{\text {out }}$ at the temperature equal to the temperature value at the beginning of the linearization range, the beginning of the first linearization range is equal to the calibration temperature.

When the compensating current passes through the PTT at the output of the IIA the voltage is formed:

$$
U_{1}=U_{b e 0}-\Delta U_{A} t-\Delta U_{B} t^{2}+I_{c} r_{i n},
$$

where $r_{i n}$ is the internal resistance of the base-emitter junction.

At equality $\Delta U_{b} t^{2}=I_{k} k_{\text {in }}$ the quadratic component of change of base-emitter voltage from temperature at the end of the range of linearization $t_{\max }$ is completely compensated.

\section{The method of linearization of the transfer function based on the change of the conversion factor of the secondary transducer}

For analogue linearization, we propose to use the method of changing the conversion factor of the output scale amplifier of the secondary transducer (SST) on separate ranges of temperature measurement. The structural scheme of a semiconductor temperature sensor with linearization of the transfer function is shown in Fig. 3.

The transistor primary temperature transducer (PTT) is connected to the device for determining the baseemitter voltage change (DDVC). In this case, a voltage, the value of which is equal to the value of the change in the base-emitter voltage from the temperature changes, is formed at the output of the DDVC.

$$
\Delta U_{t}=\Delta U_{A} t+\Delta U_{B} t^{2} .
$$

The signal from the DDVC is fed to the input of the output scale summing amplifier OSSA, at the output of which the voltage is equal to:

$$
U_{\text {out }}=\left(\Delta U_{A} t+\Delta U_{B} t^{2}\right) k,
$$

where $k$ is the gain factor of the OSSA.

The calibration at certain points of the measurement range is performed to compensate the quadratic component of the PTT transfer function. The value of the gain factor $k$ is selected from the condition of ensuring numerical equality of the value of the output voltage to the measured temperature at the appropriate point.

In order to compensate the quadratic component in the entire measurement range, a linearization device (LD) is used. It generates the voltage:

$$
U_{c}=\left[\left(\Delta U_{A} t+\Delta U_{B} t^{2}\right) k-U_{z}\right] k_{l},
$$

where $U_{z}$ is the bias voltage, the value of which is numerically equal to the value of the temperature at the calibration point; $k_{l}$ is the conversion factor of the LD.

Accordingly, the output voltage of the OSSA in the range of linearization is described by the expression:

$$
U_{\text {out }}=\left(\Delta U_{A} t+\Delta U_{B} t^{2}\right) k\left(1-k_{l}\right)+U_{z} k_{l} .
$$

The choice of nonlinearity coefficient $k_{l}$ ensures the fulfilment of the condition $\Delta U_{B} t^{2}=U_{c}$ at the end of the range of linearization. The nonlinearity error is fully compensated at this point.

\section{Investigation of the schematic diagrams of temperature sensors with linearization of the transfer function}

In accordance with the proposed structural schemes, the schematic diagrams of temperature sensors based on transistor transducers with linearization of the transfer function are developed. The model of investigation the schematic diagram of the temperature sensor with formation of compensating base current is shown in Fig. 4.

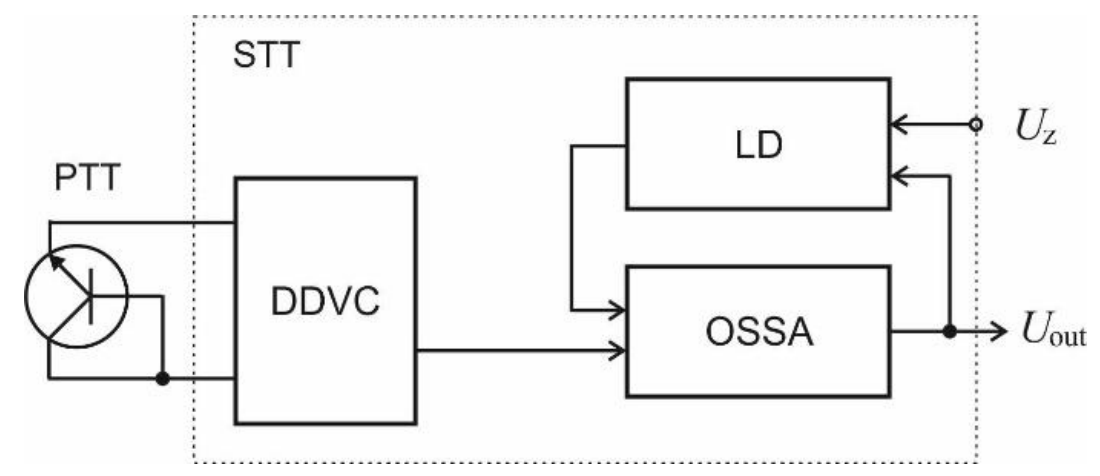

Fig. 3. Structural scheme of a semiconductor temperature sensor with linearization of the transfer function based on the change of the conversion factor of the secondary transducer. 


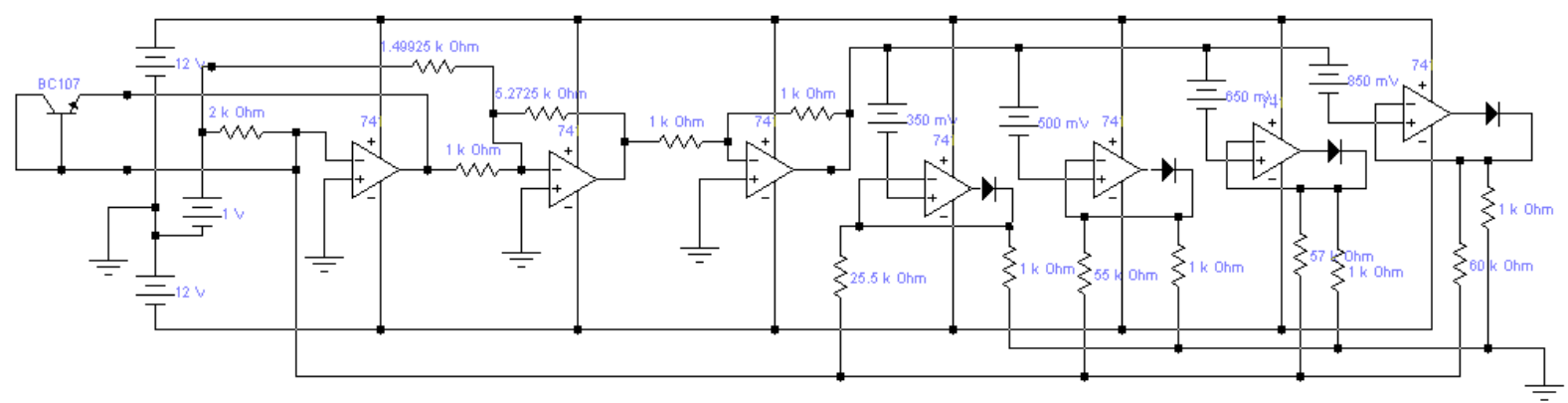

Fig. 4. Model of investigation the schematic diagram of the temperature sensor with formation of compensating base current.

The transistor primary transduser is connected into the feedback of the input operational amplifier, the inverting input of which is connected through a resistor to a source of sample voltage $U_{0}=1 \mathrm{~V}$.

Accordingly, the reference measuring current passing through the base-emitter junction is equal to:

$$
I_{0}=\frac{U_{0}}{R_{0}} .
$$

The voltage of the input operational amplifier is determined from the expression:

$$
U_{1}=-U_{b e 0}+\Delta U_{A} t+\Delta U_{B} t^{2} .
$$

The voltage of the first operational amplifier is fed to the first input of the scaling summing amplifier on the second operational amplifier. In order to compensate the initial base-emitter voltage, the reference voltage $U_{0}$ is connected to the second input of the OSSA.

In order to compensate $U_{b e 0}$ it is necessary that:

$$
\frac{U_{b e 0}}{R_{1}}=\frac{U_{0}}{R_{2}},
$$

where $R_{1}, R_{2}$ is the input summing resistors of the scale inverting amplifier, which are respectively equal to $1 \mathrm{kOhm}$ and $1.4992 \mathrm{kOhm}$.

Accordingly, the output voltage of the OSSA is equal to:

$$
U_{\text {out }}=-\left(\Delta U_{A} t+\Delta U_{B} t^{2}\right) k,
$$

where $k=\frac{R_{1}}{R_{3}}$ is the conversion factor of the OSSA, $R_{3}$ is the resistance of the feedback resistor.

A voltage, generated at the output of the third operational amplifier, is equal to:

$$
U_{3}=\left(\Delta U_{A} t+\Delta U_{B} t^{2}\right) k \frac{R_{i n 3}}{R_{z 3}},
$$

where $R_{i n 3}, R_{z 3}$ are the input and the feedback resistors of the third operational amplifier, respectively.

If $R_{i n}=R_{z}$ then

$$
U_{3}=\left(\Delta U_{A} t+\Delta U_{B} t^{2}\right) k
$$

In order to linearize the transfer function on individual measurement ranges, the appropriate circuit of compensation current formation are used. The output voltage of the temperature sensor is equal to:

$$
U_{3}=\left(\Delta U_{A} t+\Delta U_{B} t^{2}-I_{c} r_{b e}\right) k
$$

where $r_{b e}$ is the base-emitter transient resistance of the PTT, which is equal to the ratio of the voltage change at the base-emitter junction to the change in the base current $r_{b e}=\frac{\Lambda U_{b e}}{\Delta I_{b}}$.

The linearization device generates a compensation current according to the expression:

$$
I_{c}=\frac{U_{3}-U_{z}}{R_{c 1}}
$$

where $R_{c l}$ is the resistance value of the output resistor of the linearization device, which is connected to the baseemitter junction of the PTT; $U_{z}$ is the bias voltage at the input of the linearization device, which is equal to the output voltage at the beginning of the linearization range.

In order to fully compensate the quadratic component at the end of the linearization range, it is necessary to perform the equality:

$$
\Delta U_{B} t_{c 1}^{2}=I_{c} r_{b e}=\frac{U_{3 c 1}-U_{z 1}}{R_{c 1}} r_{b e} .
$$

After linearization, the output voltage is equal to

$$
U_{3}=\left(\Delta U_{A} t+\Delta U_{B} t^{2}\right) k\left(1-k_{l 1}\right)+U_{z 1} k_{l 1},
$$

where $U_{z l}, k_{l l}$ are the bias voltage and linearization factor in the first range, respectively. In this case $k_{l 1}=\frac{r_{b e}}{R_{k 1}}$.

In the second linearization range, the output voltage is described by the expression:

$U_{3}=\left[\left(\Delta U_{A} t+\Delta U_{B} t^{2}\right) k\left(1-k_{l 1}\right)+U_{z 1} k_{l 1}\right]\left(1-k_{l 2}\right)+U_{z 2} k_{l 2}$, where $U_{z l}, k_{l l}$ are the bias voltage and linearization factor in the second range, respectively.

The results of the investigation are shown in Fig. 5.

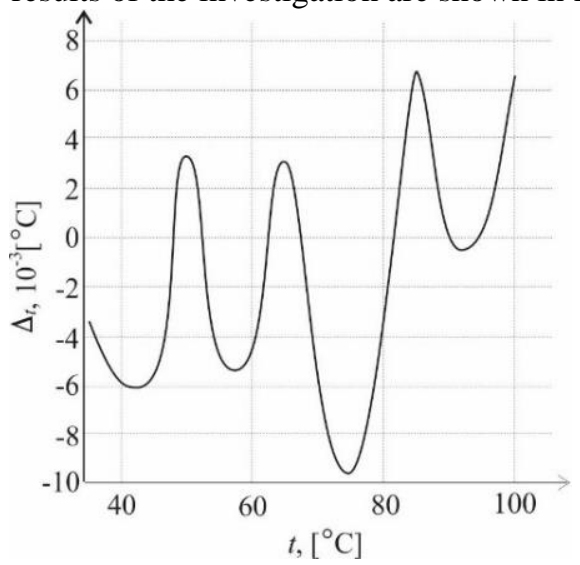

Fig. 5. Relationships between the errors of nonlinearity and the temperature. 


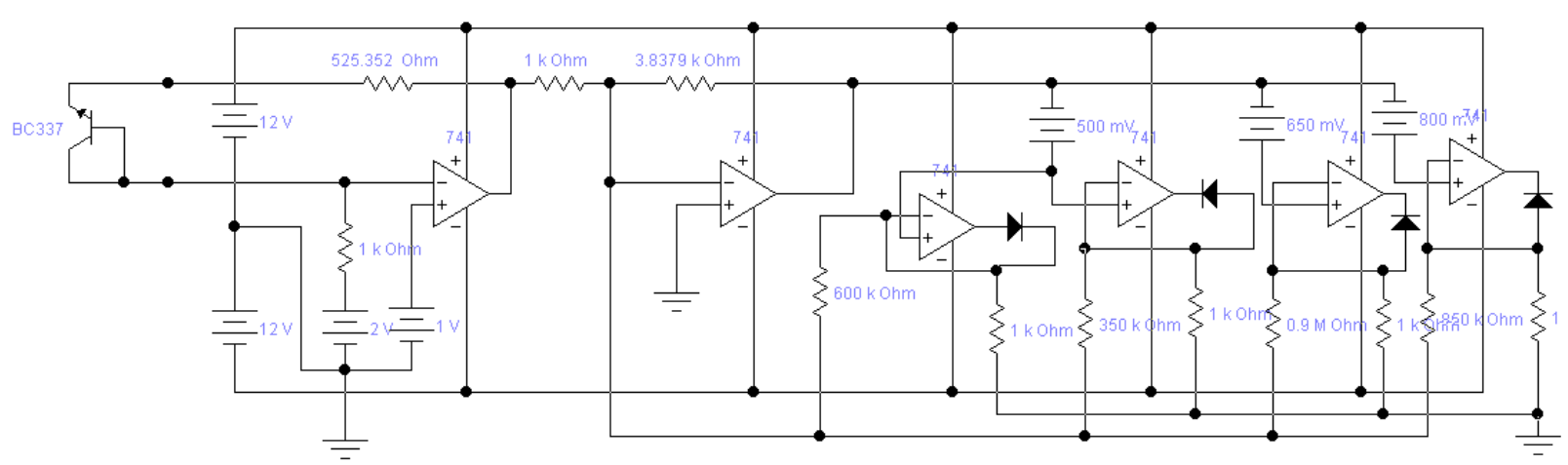

Fig. 6. Schematic diagram of a temperature sensor with a variable conversion factor of the output scaling amplifier of STT.

From the analysis of the conducted researches it can be seen that the developed schematic diagram of the temperature sensor with formation of compensating base current provides a nonlinearity error that does not exceed $0,01{ }^{\circ} \mathrm{C}$.

The model of investigation the schematic diagram of the temperature sensor with a variable conversion factor of the output scale amplifier is shown in Fig. 6.

In the schematic diagram of a temperature sensor with a variable conversion factor of the output scaling amplifier, the transistor primary transduser is connected in series with a compensation resistor connected into the feedback circuit of the input operational amplifier. In this case, the inverting input of the operational amplifier is connected through a resistor $R=1 \mathrm{kOm}$ to the reference voltage source $U_{01}=2 \mathrm{~V}$. In order to compensate the influence of the initial voltage of PTT at $0^{\circ} \mathrm{C}$, the noninverting input is connected to the reference voltage source $U_{02}=1 \mathrm{~V}$. Accordingly, the output voltage is determined from the expression:

$$
U_{1}=U_{02}-U_{b e 0}-I_{0} R_{a d}+U_{A} t+\Delta U_{B} t^{2}
$$

where $I_{0}=\frac{U_{01}-U_{02}}{R}$ is the value of the measuring current.

$$
\text { If } U_{b e 0}+I_{0} R_{a d}=U_{02} \text {, then } U_{1}=\Delta U_{A} t+\Delta U_{B} t^{2} \text {. }
$$

The output voltage of the first operational amplifier is fed to the input of the inverting scale amplifier whose output voltage is equal to:

$$
U_{2}=-\left(\Delta U_{A} t+\Delta U_{B} t^{2}\right) k,
$$

where $k$ is the conversion factor of the inverting scale amplifier.

The coefficient $k$ is chosen from the condition of equality of the output voltage value to the numerical value of the temperature at the calibration point $t_{c}=$ $50{ }^{\circ} \mathrm{C}$. After calibration, the nonlinearity of the transfer function of PTT in the range $t<t_{c}$ creates a negative error component $\Delta t<0$, and in the range $t>t_{c}$ - a positive component $\Delta t>0$.

In order to compensate the nonlinearity error, the compensating voltages of different polarities are formed by the linearization devices.

In order to compensate the nonlinearity in the range $t<t_{c}$, an operational amplifier is used, the non-inverting input of which is connected to the output of the output amplifier through the bias voltage source $U=500 \mathrm{mV}$. At a temperature $t<t_{c}$, the output voltage of the output amplifier is $\left|U_{\text {out }}\right|<\left|U_{z}\right|$, and at the output of the operational amplifier of the linearization device, a positive voltage is formed, which through the diode in the direct connection and the output resistor is fed to the input of the output amplifier. The output voltage of the output amplifier is determined from the expressions:

$$
\begin{aligned}
& U_{\text {out }}=-\left(\Delta U_{A} t+\Delta U_{B} t^{2}\right) k\left(1+k_{l 1}\right)-U_{z 1} k_{l 1}, t<t_{c}, \\
& U_{\text {out }}=-\left(\Delta U_{A} t+\Delta U_{B} t^{2}\right) k\left(1-k_{l 2}\right)+U_{z 2} k_{l 2}, t>t_{c},
\end{aligned}
$$

where $U_{z 1}$ is bias voltage; $k_{l 1}, k_{l 2}$ are linearization coefficients.

The linearization coefficients are determined by the values of the resistance of the output resistors of the LD operational amplifier and the value of the resistance of the feedback resistore of the output scale amplifier.

The results of investigation are shown in Fig. 7.

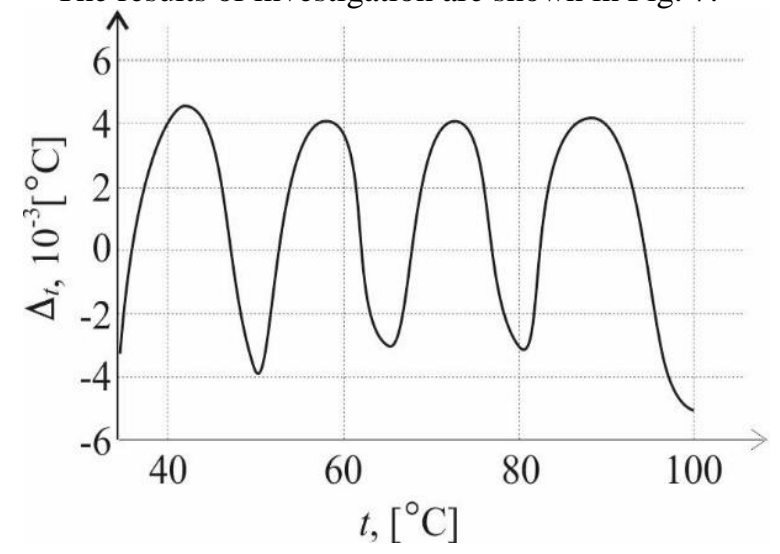

Fig. 7. Relationships between the errors of nonlinearity and the temperature.

From the analysis of the conducted researches it can be seen that the developed schematic diagram of a temperature sensor with a variable conversion factor of the output scaling amplifier of STT provides a nonlinearity error that does not exceed $0.005^{\circ} \mathrm{C}$.

Increasing the accuracy is possible by reducing the measurement range or by increasing the number of 
linearization ranges.

\section{Conclusions}

The methods of linearization of the transfer function of semiconductor temperature sensors based on the formation of compensatory base measuring current and with formation of an additional conversion factor of the output amplifier are proposed. In this case the quadratic component of the transfer function of the transistor primary transfer at different temperature ranges is compensated at individual temperature ranges of measurement. The investigation of the developed schematic diagram has shown that in the case of usage the linearisation method based on the formation of compensating base current, the measurement accuracy of $\pm 0.01{ }^{\circ} \mathrm{C}$ is provided. At the application of the method with a variable conversion factor of output scaling amplifier, the accuracy of $\pm 0.005^{\circ} \mathrm{C}$ is provided in the range $30-100{ }^{\circ} \mathrm{C}$.

Boyko O.V. - Ph.D., Associate Professor, Head of the Department of Medical Informatics;

Hotra Z.Y. - Doctor of Technical Sciences, Professor, Head of the Department of Electronic Devices.

[1] V. Naveen Kumar, K. V. Lakshmi Narayana, IET Science, Measurement \& Technology 9(8), 955(2015) (DOI:10.1049/iet-smt.2015.0008).

[2] M.A.P. Pertijs, A. Niederkorn, Ma Xu, B. McKillop, A. Bakker, J.H.A Huijsing, IEEE Journal of Solid-State Circuits. 40 (2), 454 (2005) (DOI: 10.1109/JSSC.2004.841013).

[3] C. Goumopoulos, Sensors 18(10), 3445 (2018) (DOI: 10.3390/s18103445).

[4] O. Boyko, G. Barylo, R. Holyaka, Z. Hotra, K. Ilkanych, Eastern-European Journal of Enterprise Technologies 4/9 (94), 36 (2018) (DOI: 10.15587/1729-4061.2018.139763).

[5] O. Boyko, R. Holyaka, Z. Hotra, A. Fechan, H. Ivanyuk, O. Chaban, T. Zyska, I. Shedreyeva, Proceeding of SPIE, 10808, 1080812 (2018) (DOI: 10.1117/12.2501632).

[6] B. Shi, S. Feng, Y. Zhang, K. Bai, Y. Xiao, L. Shi, C. Guo, IEEE Transactions on Power Electronics 34(10), 10136 (2019) (DOI:10.1109/TPEL.2019.2894346).

\author{
О.В. Бойко ${ }^{1}$, 3.Ю. Готра ${ }^{2}$
}

\title{
Аналіз і дослідження методів лінеаризації функції перетворення прецизійних напівпровідникових сенсорів температури
}

\footnotetext{
${ }^{1}$ Львівський начіональний медичний університет імені Данила Галицького, Львів, Украӥна, oxana_bojko@ukr.net

${ }^{2}$ Національний університет «Львівська політехніка», Львів, Украӥна, zhotra@polynet.lviv.иа
}

\begin{abstract}
Проведено аналіз нелінійності функції перетворення первинних перетворювачів температури на основі транзисторних структур, який показав, що квадратична складова функції перетворення створює значну похибку нелінійності $0,2-0,6^{\circ} \mathrm{C}$. Нами розроблено методи лінеаризації на основі формування компенсаційного вимірювального струму та на основі зміни коефіцієнта перетворення вихідного масштабуючого підсилювача на окремих температурних діапазонах вимірювання, які забезпечують їх використання в прецизійних пристроях вимірювання температури. При цьому похибка вимірювання не перевищує $0,01^{\circ} \mathrm{C}$ в діапазоні $30-100^{\circ} \mathrm{C}$.

Ключові слова: транзистор, сенсор температури, лінеаризація.
\end{abstract}

